\title{
THE ROLE OF PERIODIC EXAMINATION IN THE PREVENTION OF COALWORKERS' PNEUMOCONIOSIS
}

BY

\author{
A. L. COCHRANE, C. M. FLETCHER, J. C. GILSON, and P. HUGH-JONES \\ From the Pneumoconiosis Research Unit of the Medical Research Council, Llandough Hospital, Nr. Cardiff
}

There can be no doubt that coalworkers' pneumoconiosis presents one of the most serious problems in industrial medicine in Britain, at least in respect of the numbers of men affected. From 1931 up to the end of 1949 some 36,000 men had been officially diagnosed by the Silicosis Medical Board or the Pneumoconiosis Panels of the Ministry of National Insurance as being disabled by the disease. Over $80 \%$ of these cases had arisen in the South Wales coalfield. The social consequences of the disease in South Wales have been reviewed by Hugh-Jones and Fletcher (1950). The cost of the disease in terms of compensation has been enormous and in terms of human suffering immeasurable.

The disease is one that has been shown to be due to the inhalation of coal dust (Hart and Aslett, 1942) and its ultimate control and prevention will come from dust suppression. Airborne dust concentrations underground must be reduced to levels at which they will not cause pneumoconiosis in men exposed to them throughout a normal working life.

Coal dust in some mines appears to be less dangerous than in others. But since the factors which may make coal dust dangerous are not yet known, the precise levels of dust concentration in different pits which may be regarded as safe are uncertain, and indeed they cannot be established until a generation of coal miners has been exposed to them for their working life and has been shown to remain healthy. At present the Ministry of Fuel and Power and the National Coal Board have accepted as provisional levels for "approved dust conditions " under which men may be expected to work with reasonable safety, 650 particles/cc.* between 1 and 5 microns in anthracite pits and 850 particles/cc., within the same size range, in steam and bituminous coal pits. This expectation is, however, based on scanty evidence (Bedford and Warner, 1942), and the approved dust levels

\footnotetext{
* Estimated by the thermal precipitator.
}

are really no more than a provisional target for engineers engaged on dust suppression.

Since the complete suppression of all airborne dust in the mines is impracticable and safe levels of dustiness are not yet known, we believe that the introduction of a system of periodic medical examination of coal miners would be the procedure which would most quickly and economically lead to the prevention of pneumoconiosis.

All coal miners in France and in New South Wales are given a periodic medical examination, and this system is being introduced into the coal mines of South Africa and Belgium. Since the value of such an examination has recently been questioned by Meiklejohn (1950) we review the advantages it could bring in British coal mines.

\section{The Objects of Periodic Examination}

A system of periodic examinations would have three main advantages.

First, it would provide an immediate protection to the men in the interval before safe dust levels are defined and effective dust suppression achieved. This would be possible because symptoms and disability develop late in the course of coalworkers' pneumoconiosis while radiological changes, which indicate a danger of ultimate disability, nearly always appear before functional injury has been done to the lungs. Permanent injury could be prevented in men showing these early radiological changes if they were advised to work under conditions of reduced dust exposure.*

Secondly, it would reveal the mines, seams or even districts, where early signs of the disease were still arising, in spite of dust suppression, so that the attention of the engineers could be concentrated

*It has been stated (Lehmann, 1938 ; Craw, 1947 ; Smith, 1947) that some men are more susceptible to the effects of dust than others. But the methods suggested for detecting these men are so imprecise that serious manpower wastage would occur if all doubtful cases that serious manpower wastage would occur if all doubtful cases be detected by their earlier development of abnormality on serial $x$-ray examination. 
at appropriate places. To suppress dust where the disease is not arising is an economic and technical waste since the cost of dust suppression rises steeply as more control is demanded ; the law of diminishing returns applies forcibly after the simpler methods of dust suppression have been installed. We have seen noticeable radiographic changes occurring in previously normal men after only two and a half years' exposure to dust concentrations somewhat in excess of "approved" conditions, so that radiological control should provide biological evidence of inadequate dust control within a period short enough for effective action to be taken.

Thirdly, if periodic examination were combined with routine dust studies at representative pits throughout the country, it should be possible in the course of time to determine the level of dustiness which had not given rise to any pneumoconiosis. In this way "safe" standards of dustiness could be defined and so permit adequate dust control by physical methods. It is conceivable that such an investigation might also throw light on the special features of the different dusts that are responsible for their varying pathogenicity, and so assist in predicting safe conditions for new mines.

\section{The Basis of Periodic Examination}

The last two objectives of periodic examination which we have outlined above, those leading to the maintenance of a safe working environment by dust suppression, require no further justification. The first, that of providing immediate protection for the men, depends on two pieces of medical evidence, namely (1) that early radiological changes can be detected before serious disablement occurs ; (2) that if men with these early radiological changes are no longer exposed to dangerous dust, they will not. become disabled by the dust that they have already retained in their lungs. This evidence will therefore briefly be reviewed.

(1) Disability in Relation to Radiological Change. -There are two types of radiological change which may occur in coalworkers' pneumoconiosis : " simple pneumoconiosis" and "progressive massive fibrosis", P.M.F., (Fletcher, 1948). There is evidence both from pathological (Gough, 1949 ; Heppleston, 1947) and radiological follow-up studies (Davies, Fletcher, Mann, and Stewart, 1949) to suggest that each represents a distinct pathological process. The combination of simple pneumoconiosis and progressive massive fibrosis has been called "complicated pneumoconiosis".

A quantitative radiological classification (Fletcher, Mann, Davies, Cochrane, Gilson, and Hugh-Jones, 1949) defining four categories of increasing amounts of simple pneumoconiosis (categories 1-4) and four of progressive massive fibrosis (categories A-D) will be used throughout this paper.

Simple Pneumoconiosis.-Coal dust which is retained in the lungs gradually accumulates in small, scattered, discrete foci (Heppleston, 1949 ; Gough, James, and Wentworth, 1949) and this process is seen radiologically by the gradual appearance of characteristic minute opacities.

Progressive Massive Fibrosis.-This process is characterized pathologically by the development of larger nodules of collagenous flbrosis (called " infective" nodules by Gough) which are seen on the radiograph as massive shadows (" massive consolidation" of Sutherland and Bryson, 1929 ; " conglomerate shadows" of Bloomfield, Dallavalle, Jones, Dreessen, Brundage, and Britten, 1935 ; " images pseudo tumorales" of Eck and Hanaut, 1944 ; etc.).

The M.R.C. Pneumoconiosis Research Unit has recently investigated the relation between these radiological appearances of pneumoconiosis and the degree of respiratory disability in different age groups of South Wales coal miners, using clinical assessment and a variety of physiological tests.

The subjects were selected by their age and their radiological category of pneumoconiosis, and men were rejected from the experimental group only if they had a disease other than pneumoconiosis which might independently affect their respiratory function, e.g. hypertension, chest injury, etc. Normal subjects chosen as controls were men who had never worked in the coal mines; the majority were attending the Ministry of Labour's employment exchanges between jobs. A full account of this investigation will be published elsewhere.

It was found that excessive breathlessness on effort, the main disability in pneumoconiosis, was not caused by a marked increase in the ventilatory requirements for a given amount of exercise, but by a decrease in the ventilatory reserve. Reduction in the maximum breathing capacity test (M.B.C.) was found to be the best simple index of this lowered reserve and to be closely related to the man's complaint of breathlessness on exercise. This is generally accepted (Böhme, 1938 ; Jequier-Doge and Lob, 1944; Rossier, Bucher and Wiesinger, 1947; Baldwin, Cournand, and Richards, 1948), and here we shall only consider the results obtained with this test. The test was done in the manner described by Gilson and Hugh-Jones (1949) and the results are given in Table 1.*

\footnotetext{
* D'Silva and Mendel (1950) showed that the M.B.C. measured with a water spirometer might be subject to considerable error. We have fully investigated the errors of the test in the circumstances in which our results were obtained; they ar
} 
TABLE 1

MEAN MAXIMUM BREATHING CAPACITY (LITRES/MIN.) IN THREE DIFFERENT AGE GROUPS OF MINERS AND OTHERS AT DIFFERENT RADIOLOGICAL STAGES OF PNEUMOCONIOSIS*

\begin{tabular}{|c|c|c|c|c|c|c|}
\hline \multirow{3}{*}{ Age (years) } & \multirow{3}{*}{$\begin{array}{c}\text { Men without } \\
\text { Chest Disease } \\
\text { X }\end{array}$} & \multirow{3}{*}{$\begin{array}{c}\text { Miners with Less } \\
\text { than Category } 1 \\
\text { Simple } \\
\text { Pneumoconiosis } \\
\text { O }\end{array}$} & \multicolumn{2}{|c|}{$\begin{array}{l}\text { Miners with Simple } \\
\text { Pneumoconiosis }\end{array}$} & \multicolumn{2}{|c|}{$\begin{array}{l}\text { Miners with Progressive } \\
\text { Massive Fibrosis }\end{array}$} \\
\hline & & & $\begin{array}{c}\text { Early } \\
\text { (Category } 1 \text { \& 2) }\end{array}$ & $\begin{array}{c}\text { Advanced } \\
\text { (Category 3 \& 4) }\end{array}$ & $\begin{array}{c}\text { Moderate } \\
\text { (Stage B \& C) }\end{array}$ & $\begin{array}{l}\text { Advanced } \\
\text { (Stage D) }\end{array}$ \\
\hline & & & $\Theta$ & 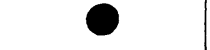 & 口 & 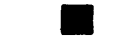 \\
\hline $\begin{array}{c}35 \\
(1 \cdot 4)\end{array}$ & $\begin{array}{l}145 \\
(30 \cdot 0) \\
N=10\end{array}$ & $\begin{array}{l}119 \\
(29 \cdot 2) \\
\mathrm{N}=18\end{array}$ & $\begin{array}{l}115 \\
(31 \cdot 5) \\
N=29\end{array}$ & $\begin{array}{l}135 \\
(22 \cdot 4) \\
N=8\end{array}$ & $\begin{array}{l}98 \\
(23 \cdot 8) \\
N=8\end{array}$ & $\begin{array}{l}65 \\
(19 \cdot 8) \\
N=6\end{array}$ \\
\hline $\begin{array}{c}45 \\
(1 \cdot 9)\end{array}$ & $\begin{array}{l}131 \\
(18 \cdot 6) \\
N=10\end{array}$ & $\begin{array}{l}109 \cdot 5 \\
(26 \cdot 4) \\
N=19\end{array}$ & $\begin{array}{l}110 \\
(24 \cdot 2) \\
N=27\end{array}$ & $\begin{array}{l}101 \\
(28 \cdot 2) \\
\mathrm{N}=8\end{array}$ & $\begin{array}{l}79 \\
(31 \cdot 6) \\
N=8\end{array}$ & $\begin{array}{l}51 \\
(22 \cdot 5) \\
N=8\end{array}$ \\
\hline $\begin{array}{c}55 \\
(1 \cdot 7)\end{array}$ & $\begin{array}{l}118 \\
(27 \cdot 6) \\
N=10\end{array}$ & $\begin{array}{l}84 \\
(28 \cdot 4) \\
N=31\end{array}$ & $\begin{array}{l}97 \\
(30 \cdot 5) \\
\mathrm{N}=30\end{array}$ & $\begin{array}{l}87 \\
(22 \cdot 3) \\
N=16\end{array}$ & $\begin{array}{l}61 \\
(7 \cdot 6) \\
N=8\end{array}$ & $\begin{array}{l}33 \\
(10 \cdot 7) \\
N=8\end{array}$ \\
\hline
\end{tabular}

* The standard deviation is given in parenthesis. $\mathbf{N}=$ number of subjects.

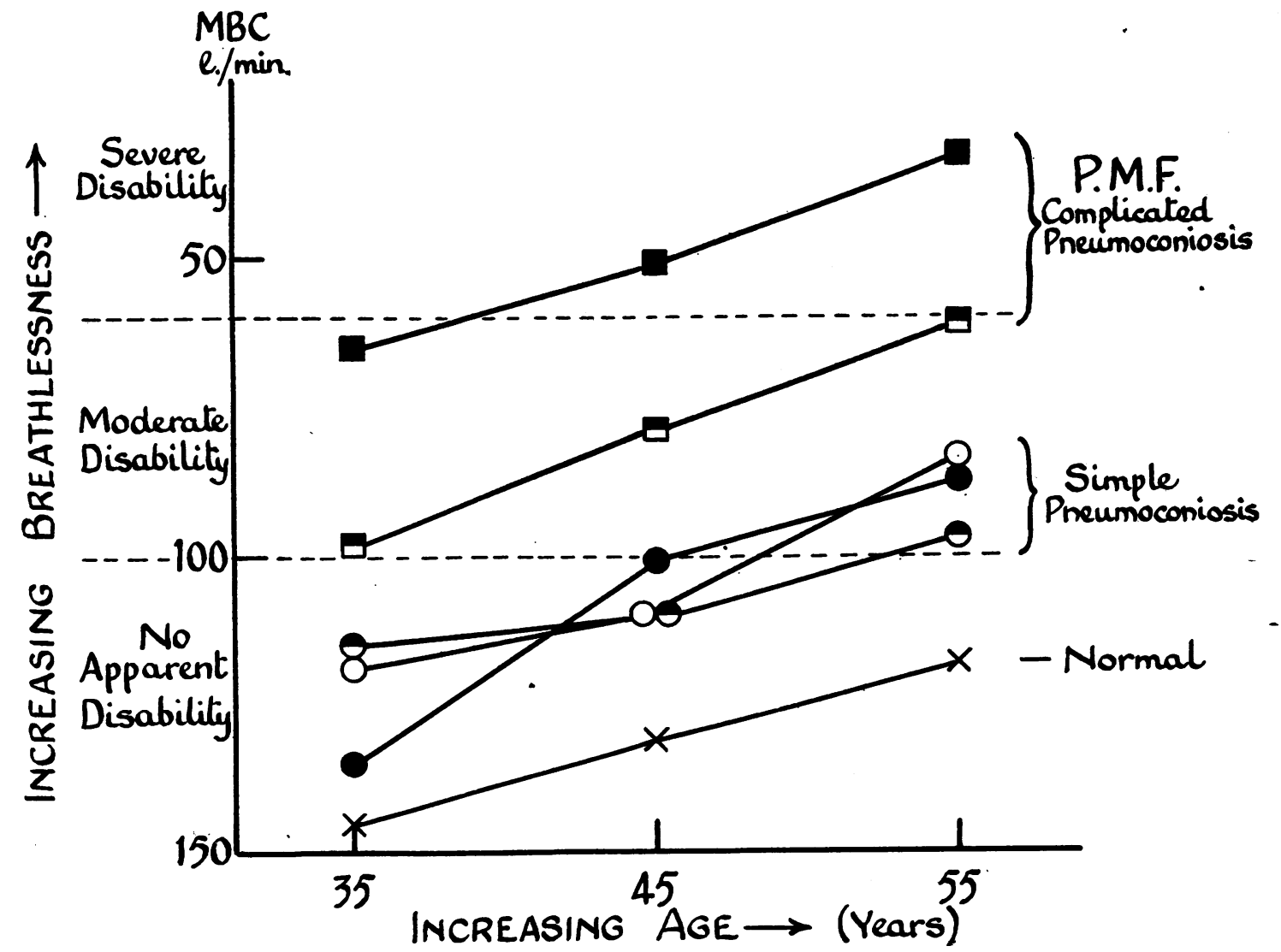

Fig. 1.-The results given in Table 1 plotted graphically. These emphasize the disability of cases of P.M.F. relative to age compared with that in cases of simple pneumoconiosis. (For meaning of symbols see Table 1.) 
It will be seen from Table 1 that in each radioogical group there is a decrease in the maximum breathing capacity with age, but in all age groups the maximum breathing capacity of the subjects who have progressive massive fibrosis is markedly reduced compared with those who only have simple pneumoconiosis. These findings are seen more clearly when the results in Table 1 are plotted graphically (Fig. 1).

From Fig. 1 it can be seen that cases of simple pneumoconiosis have on the average only a moderate systematic increase of the normal impairment of M.B.C. which occurs with age, and the radiological category of simple pneumoconiosis appears to have relatively little influence.* What is important for our purpose is that, on the average, young men even with quite advanced simple pneumoconiosis are not seriously disabled. Men with progressive massive fibrosis, on the other hand, are usually quite markedly disabled and their disability increases both with age and the radiological degree of the P.M.F.

Other workers have come to similar conclusions. Hart and Aslett (1942) found that coal miners with " reticulation" (the approximate equivalent of simple pneumoconiosis) only had a significantly greater degree of respiratory disability than miners with normal radiographs in the age groups 40-64, whereas in all age groups cases of " consolidation" (the equivalent of complicated pneumoconiosis) were considerably more disabled than men with either normal radiographs or with " reticulation". Wright (1946), who considers respiratory disability to occur in coalworkers' pneumoconiosis only when " benign" anthracosis is complicated by silicosis, found that "simple discrete nodular silicosis is, with rare exceptions, entirely compatible with a working capacity adequate to allow full employment" but that "conglomerate shadows" are often seriously disabling. Bruce (1942) and Rossier, Bucher, and Wiesinger (1947) found that it was only in "silicosis stage III" (the equivalent of massive fibrosis) that any marked disability occurred.

There are, however, other workers who assert that the disability in pneumoconiosis bears no relation to the radiological appearances : for example, Peterson, Peterson, and Startup (1939) working with 36 South Wales coal miners ; Motley, Lang, and Gordon (1949) working with 100 American anthracite miners and later with 56 bituminous coal

\footnotetext{
* It will be noted that the average M.B.C. of miners with less than radiological category 1 simple pneumoconiosis is less than the corresponding average for the normal in all age groups not engaged, in coal mining. Much larger groups of men including "normal" subjects from different industries in South Wales, would be necessary subjects from different industries in South Wales, would be necessary however, that the radiographs of those miners with minimal changes of pneumoconiosis could be distinguished from radiographs of non-miners by skilled observers.
}

miners (Motley 1950). , These opinions are based on results which are difficult to interpret since they were derived from samples which may have been biased towards more disabled men, and full allowance was not made for age. That this could explain anomalous findings is evident from Table 1 in which the wide divergence of individual results about the group means is given.

(2) The Progression of Pneumoconiosis after Cessation of Dust Exposure.-Our only evidence about the effects of pneumoconiosis once exposure to dangerous dust has ceased is from radiological studies.

Simple Pneumoconiosis.-Cases of simple pneumoconiosis can progress radiologically in two ways : the simple pneumoconiosis may increase as such, or progressive. massive fibrosis may supervene. Davies and others (1949) showed that in the absence of coal dust inhalation no increase in the severity of the radiographic appearance of simple pneumoconiosis was seen over periods up to 10 years. Recently, in the course of follow-up studies of a Welsh steam-coal colliery, it was possible to obtain further evidence. Here $75 \%$ of the underground workers were examined by $x$ rays in 1947 and again two and a half years later in 1949. The findings are given in Table 2. It will be seen that progression of simple pneumoconiosis only occurred in men who had been exposed to dust during the interval between the two surveys. No evidence is available on the progression of simple pneumoconiosis over longer periods than those covered in these two investigations.

The Onset of Progressive Massive Fibrosis.-Hart and Aslett (1942) reported that massive shadows in coalworkers' pneumoconiosis (the equivalent of P.M.F.) always appeared on a background of reticulation (the equivalent of simple pneumoconiosis) and we have confirmed this fact in all our studies of the disease.*

The question arises as to how much simple pneumoconiosis must be present before massive fibrosis may supervene and whether it can do so after the cessation of dust exposure.

Davies and others (1949) reported that $98 \%$ of caseś of early massive fibrosis had a background of category 3 or 4 simple pneumoconiosis. This suggested that massive fibrosis only arose in cases with more than the lower limit of category 3 simple pneumoconiosis. If this were so, cases with category 1 or 2 simple pneumoconiosis should not be liable to massive fibrosis. Sometimes,

\footnotetext{
* In cases of advanced massive fibrosis, concomitant bullous emphysema may obscure the simple pneumoconiosis. This may account for the occasional case of massive fibrosis without associated account for the occasional case of massive fibrosis with
simple pneumoconiosis described by McVittie (1949).
} 
TABLE 2

RADIOLOGICAL PROGRESSION OF SIMPLE PNEUMOCONIOSIS IN THE UNDERGROUND' POPULATION OF A WELSH STEAM COAL COLLIERY DURING $2 \frac{1}{2}$ YEARS

\begin{tabular}{|c|c|c|}
\hline $\begin{array}{l}\text { Occupation during } \\
\text { Interval }\end{array}$ & $\begin{array}{l}\text { No. Showing } \\
\text { Definite } \\
\text { Progression* } \\
\text { in 2! Years }\end{array}$ & $\begin{array}{c}\text { Total No. } \\
\left(\left(_{0}^{0}\right)\right.\end{array}$ \\
\hline Coal face work & 11 & $123 \quad(8.9)$ \\
\hline Stone work $\ldots$ & 7 & $97 \quad(7 \cdot 2)$ \\
\hline Mixed stone and coal. . & 2 & $50 \quad(4 \cdot 0)$ \\
\hline $\begin{array}{l}\text { Miscellaneous under- } \\
\text { ground }\end{array}$ & 4 & $79 \quad(5 \cdot 1)$ \\
\hline $\begin{array}{l}\text { Minimal exposure } \\
\text { (haulage, etc.) }\end{array}$ & 2 & $95 \quad(2 \cdot 1)$ \\
\hline Outside mining & 0 & $35 \quad(0 \cdot 0)$ \\
\hline Dead or not followed. . & - & $15-$ \\
\hline Total $\ldots$ & 26 & $494 \dagger(5 \cdot 3)$ \\
\hline $\begin{array}{l}\text { Massive fibrosis obscu } \\
\text { ground of simple pn }\end{array}$ & $\begin{array}{l}\text { ring the back- } \\
\text { eumoconiosis }\end{array}$ & - \\
\hline Total & . & 499 \\
\hline
\end{tabular}

however, it is difficult to read the radiological amount of simple pneumoconiosis when massive fibrosis has supervened and there is also the possibility that the simple pneumoconiosis may have progressed while the massive fibrosis was appearing. It is the category of the simple pneumoconiosis at the time of onset of the massive fibrosis that we really need to know.

Evidence of this nature was obtained during the follow-up study of the Welsh steam-coal colliery already described. In this study progressive massive fibrosis did not develop in any case with category 1 simple pneumoconiosis, but it did develop in some cases with category 2 as well as in those with category 3 simple pneumoconiosis; moreover, the attack rate was no less in category 2 than in category 3 cases (Table 3 ).

It appears that as simple pneumoconiosis progresses, there is an increasing liability to develop P.M.F. and that there is a relatively rapid increase in this liability within the stage of simple pneumoconiosis covered by category 2. This led Fletcher (1950) to suggest that there was a "critical stage" of simple pneumoconiosis at which liability to P.M.F. arose. The range of simple pneumoconiosis over which a significant risk of P.M.F. arises may
TABLE 3

ATTACK RATE* OF EARLY PROGRESSIVE MASSIVE FIBROSIS IN THE SAME POPULATION AS IN TABLE 2

\begin{tabular}{|c|c|c|c|c|}
\hline $\begin{array}{c}\text { Initial } \\
X \text {-ray } \\
\text { Category }\end{array}$ & $\begin{array}{c}\text { Dead } \\
\text { or } \\
\text { Untraced }\end{array}$ & $\begin{array}{l}\text { Number } \\
\text { Develop- } \\
\text { ing Early } \\
\text { P.M.F. }\end{array}$ & $\begin{array}{c}\text { Total } \\
\text { No. }\end{array}$ & $\begin{array}{c}\text { Annual } \\
\text { Attack } \\
\text { Rate } \\
\left(\begin{array}{l}\prime \\
0\end{array}\right)\end{array}$ \\
\hline $\mathrm{N}$ & 6 & 0 & 170 & 0 \\
\hline 1 & 1 & 0 & 124 & 0 \\
\hline 2 & 4 & 6 & 95 & $2 \cdot 5$ \\
\hline 3 & 2 & 4 & 72 & $2 \cdot 2$ \\
\hline Total .. & 13 & 10 & 461 & 0.9 \\
\hline $\begin{array}{l}\text { Number wh } \\
\text { in } 1947\end{array}$ & $\begin{array}{c}\text { already } h \\
.\end{array}$ & $\begin{array}{c}\text { Ad P.M.F. } \\
\ldots \quad \ldots\end{array}$ & 37 & - \\
\hline Total & . & . & 499 & - \\
\hline
\end{tabular}
per year.

vary in different parts of the country, and its exact definition must await the examination of larger numbers of cases. This could be done in the pilot scheme we propose below.

Davies and others (1949) also gave evidence to show that once a man has the requisite amount of simple pneumoconiosis his chance of developing massive fibrosis was independent of further dust exposure, and that massive fibrosis was nearly always progressive. This independence of dust exposure and attack rate of progressive massive fibrosis was again found in our recent follow-up study (Table 4).

We may summarize these radiological observations concerning the onset of massive fibrosis by saying that (1) if a man is removed from further exposure to dangerous dust when he has only a small amount of simple pneumoconiosis, he is most unlikely to develop progressive massive fibrosis ; (2) once a man has enough simple pneumoconiosis, progressive massive fibrosis may develop with equal likelihood whether or not dust exposure ceases ; (3) once massive fibrosis has started it is nearly always progressive, though at widely varying rates. We must emphasize that these conclusions only concern coalworkers' pneumoconiosis and are not necessarily applicable to silicosis.

The Significance of the Radiological Findings.The importance of these findings is that they suggest how men might be protected from disabling pneumoconiosis by periodic $x$-ray examination. If men are prevented from developing more than early simple pneumoconiosis we know that they will not develop progressive massive fibrosis with its 
TABLE 4

- ANNUAL ATTACK RATE OF PROGRESSIVE MASSIVE FIBROSIS IN CASES OF SIMPLE PNEUMOCONIOSIS (CATEGORIES 2 AND 3 FROM TABLE 3) ANALYSED BY OCCUPATION DURING THE INTERVAL

\begin{tabular}{lc|c|c|c}
\hline \multicolumn{1}{c|}{ Occupation } & $\begin{array}{c}\text { Total } \\
\text { No. }\end{array}$ & $\begin{array}{c}\text { No. } \\
\text { Attacked } \\
\text { by P.M.F. }\end{array}$ & $\begin{array}{c}\text { Annual } \\
\text { Attack } \\
\text { Rate of } \\
\text { P.M.F. }\end{array}$ \\
\hline Coal face work. . & $\ldots$ & 49 & 3 & $2 \cdot 4$ \\
\hline Stone work.. & $\ldots$ & 19 & 2 & $4 \cdot 2$ \\
\hline Mixed stone and coal .. & 17 & 1 & $2 \cdot 4$ \\
\hline Miscellaneous . . & $\ldots$ & 42 & 2 & $1 \cdot 9$ \\
\hline Minimal (haulage, etc.) & 21 & 1 & $1 \cdot 9$ \\
\hline Outside mining & $\ldots$ & 13 & 1 & $3 \cdot 1$ \\
\hline Dead or untraced & $\ldots$ & 6 & - & - \\
\hline \multicolumn{1}{c|}{ Total . . } &. & 167 & 10 & $2 \cdot 4$ \\
\hline
\end{tabular}

attendant disability. We can presume that they will not become significantly disabled by a small degree of simple pneumoconiosis (Table 1 and Fig. 1). An essential point in our argument is that since the early stages of simple pneumoconiosis are asymptomatic they can only be detected with certainty, and the men given suitable advice, by a system of periodic $x$-ray examination.

\section{Practical Considerations}

Advice after Examination.-From the foregoing discussion we can consider the advice that men should receive after their examination so that the greatest amount of protection may be given with the least possible interference with coal production. The advice would depend upon radiological appearances and age, though disability and economic factors would also have to be considered. According to their radiological appearances, the men would be grouped into two classes: (1) new entrants, men without pneumoconiosis, and men with only the very earliest radiological signs of pneumoconiosis. These men could from the start of the scheme obtain freedom from the risk of serious pneumoconiosis. They would be advised to change to a less dusty working environment if, on serial examination, they began to show evidence of simple pneumoconiosis whose severity was approaching the level at which a significant risk of massive fibrosis arises. The most important factor in giving this advice would be the rate of development of simple pneumoconiosis from one examination to the next. Age and industrial history would also have to be taken into account : a man of 55 who has early simple pneumoconiosis and has worked in the mines all his life is clearly unlikely to progress significantly in the rest of his working life. On the other hand, a man of 25 or 30 with the same radiological appearance may be running a serious risk. (2) Men who were found to have advanced simple pneumoconiosis or who had already contracted P.M.F. would not derive much benefit from periodic examination. They are the victims of the past. In view of the present evidence that the dust exposure has little effect on their liability towards progression they should as a rule not be advised to change their working environment.* The only basis for advising a man in this second group to leave the industry would be on account of disability, for it is clearly futile to advise a man to continue at a job of which he is already physically incapable. Moreover, certain cases, which on re-examination showed rapid radiological progression, might well be advised to leave mining, for it could confidently be forecast that they would become seriously disabled in the future and when they did so they might well blame this on having continued work. A small number of such cases might bring the system of advice into disrepute.

Obviously, in individual cases, there might be exceptions to the advice we have suggested. For example, if a young man were showing early radiological changes and less dusty working conditions were not available, he might still be advised temporarily to hold his job within the industry in areas such as South Wales, where there are slender chances of obtaining immediate alternative employment. The disease develops very slowly and there is no hurry for a man to leave the industry while seeking another job.

The phrase "less dusty working conditions" needs some comment. Men who are showing progression of simple pneumoconiosis in spite of exposure to relatively low dust conditions should be removed from any further dust exposure-by leaving the industry or taking up surface work. On the other hand, if the progression could be attributed to working in high dust concentrations, change to a less dusty, even if not dust-free environment, might be sufficient to arrest progression. It is thus apparent that in order to give appropriate advice doctors would have to have full information concerning the dust concentrations under which the

\footnotetext{
* In the course of periodic examination knowledge of the precise relationship between the attack rate of P.M.F. and the severity of simple pneumoconiosis would increase and some men who already had fairly advanced simple pneumoconiosis might come to be classified with the first group of early cases. This is especially true in coalfields outside South Wales where our knowledge of the relation in coalfields outside South Wales where our knowledge of the relation
between the degreè of simple pneumoconiosis and chance of contracting P.M.F. is slight.
} 
men had been working since the last examination, and concerning the concentrations prevailing at the alternative, less dusty working places that the N.C.B. could offer to them. There is real need for some form of continuous dust-sampler which could be used in assessing dust levels under " approved conditions". This, used in conjunction with periodic examination, would show whether these conditions are, in fact, safe.

We may summarize by saying that the only men who would have to be advised to leave the industry or to change their occupation to one involving less dust exposure would be those with early simple pneumoconiosis which was found to be advancing on serial $x$-ray examination, especially if they were young, and those with more advanced radiological changes who were becoming disabled by the disease.

Compensation.-The purpose of the scheme is the prevention of disability. This should be made quite clear to the men by making it independent from any question of compensation. If the scheme were also concerned with compensation the emphasis would be removed from fit men whose health must be preserved to disabled men to whom little but financial compensation could be offered.

Men with pneumoconiosis who claimed disability could be referred to the Pneumoconiosis Medical Panels for disability assessment. $X$-ray examination under the periodic system could achieve an enormous economy by replacing the scrutiny examination at present carried out by the Pneumoconiosis Panel whose duties would then be confined to their statutory function of assessing disability and its cause. Arrangements would have to be made for the radiographs taken in the course of periodic examination to be lent to the Pneumoconiosis Panel.

If compensation issues were kept separate in this way, clinical examination could be confined to special cases. Radiological examination alone should suffice to detect the earliest stages of pneumoconiosis and to follow its progression towards dangerous levels.

Meiklejohn (1950) has objected that " the worker and his union will want to know whether he has contracted pneumoconiosis, not if he has reached the critical level of severity". It is difficult to understand when a man can be said to have " contracted pneumoconiosis" since simple pneumoconiosis develops from normality by a gradual and continuous process. Experience has shown that miners are perfectly willing to accept the idea that there may be some evidence of dust in their lungs without there being any disease, by simple analogy with the fact that they commonly have dust in the "blue scars" on their skin without their having skin disease. The men's right to apply to the Pneumoconiosis Panel for compensation for disability would, of course, remain.

One alteration in the present system of compensation would be necessary: under the National Insurance (Industrial Injuries) 1946 Act no provision is made for giving compensation to men who, as a result of developing an early stage of an industrial disease, have to be advised to change their occupation although they are not disabled. Thus young men who would have to be advised to leave the coal mining industry under a system of periodic examination could at present receive no financial compensation. This defect in the provision of compensation would require rectification, possibly by legislation, if the scheme of periodic examination were to be a success.

The Introduction of the System.-In the organization of a scheme, such as we have outlined, there would be many administrative and technical problems whose importance cannot be forecast and whose solution could not be suggested in advance of the introduction of the scheme. For instance, we do not know the prevalence of unrecognized pneumoconiosis in various coalmining areas, which would largely determine the appropriate interval between examinations ; what effect the examinations would have on the number of applications for disability benefit to the Pneumoconiosis Panel; what staff (medical, technical, and administrative) would comprise an efficient unit, and what the operational costs of such a unit would be ; or how far and in what way arrangements would be made by the N.C.B. for young men with early pneumoconiosis to continue working in the mines under conditions of minimal dust exposure. Because of all these uncertainties it is our view that periodic examinations should first be introduced on a pilot basis.

Since new entrants and young men would derive the greatest benefit from examinations it might be suggested that the system should in the first place be confined to the younger workers or even to new entrants to the industry. Periodic examinations would have little to offer to men who had already reached an age at which further serious progression would be unlikely to occur before the normal retiring age or to men who already had relatively advanced pneumoconiosis. However, it is our belief that it would in fact be administratively simpler and psychologically better to extend the examinations to include all underground workers in whatever pits were chosen for introducing the scheme.

The next question is whether all underground 
workers could be examined unless the system were made compulsory. In underground surveys carried out on a voluntary basis by the Pneumoconiosis Research Unit's mobile unit at six different collieries, four in South Wales and two elsewhere in Britain, over $99 \%$ of the workers have been examined. This high percentage was achieved by obtaining the full cooperation of the trade unions, by active propaganda and, by offering examinations and subsequent interviews from 10 a.m. to 11 p.m. Routine examinations could not be made on this basis, but if the N.C.B. gave men time off without loss of pay in order to attend for examination in a mobile $x$-ray unit, there should be no difficulty in obtaining practically universal examination without any form of compulsion.

The main difficulty would be to decide where the pilot scheme should be started. Since in South Wales the Pneumoconiosis Panels are already being used by the men as an irregular system of periodic examination, the scheme might well start there. Later, when any preliminary difficulties had been overcome, the scheme should start, on a voluntary basis, in mines representative of various areas in the different coalfields; it may be that some of our conclusions are not applicable to pneumoconiosis arising in other coalfields, particularly in respect to the relationship between severity of simple pneumoconiosis and liability to massive fibrosis. Such gaps in our knowledge could be filled in the course of a few years by the pilot scheme provided that it was so designed that the records and results obtained from it could be used for research purposes. This would entail adequate provision for following-up men who leave the industry or move from one mine to another in the various coalfields. Many of the doubts and fears expressed by Meiklejohn (1950) would be resolved by a scheme introduced in this way.

Interval between Examinations.-The interval between examinations would vary from one part of the country to another but the pilot scheme would enable satisfactory intervals to be determined. In mines where the dust conditions were not satisfactory and where new cases of disease were appearing, it would have to be of the order of a year. In some parts of the country it would be unnecessary to have the examinations at more frequent intervals than three or four years unless practical experience showed that it was impossible to keep track of men examined, for little change in the extent or prevalence of the disease could be determined in a shorter interval than this.

Nature of the Examination.-We have indicated that the basis of the examination need only be radiological. At present no miniature radiographic technique is adequate for the early diagnosis of simple pneumoconiosis (Fletcher, 1951). It would therefore be necessary to use full size films. The M.R.C. mobile unit is capable of taking 20 full size radiographs per hour and processing them to the finished dry stage. This would probably be a sufficient speed of work for any field survey. Each mobile unit could work a 35-hour week : a sevenhour day for.five days. Allowing 17 weeks a year for movement from place to place and for holidays, they would work 35 weeks in the year. At this rate each unit could take 24,500 films per year and 10 such units could easily examine the 700,000 men of the country with an average interval of two and a half to three years between examinations. This should be quite adequate.

The question still arises whether even large films would enable accurate diagnosis of early simple pneumoconiosis to be made. In view of the work reported by Fletcher and Oldham (1949) on the inconsistencies of radiological diagnosis, it would be necessary for the doctors running the scheme to pass some test of their ability to read films of early simple pneumoconiosis accurately and consistently.

Errors will occur even with the most skilled reader. For this reason Meiklejohn (1950) suggests that it might not "be prudent at this stage to proceed, recognizing as we must that the decisions involve human welfare and happiness". There are two possible errors of diagnosis which might cause human unhappiness. The first would be the failure to detect pneumoconiosis in a man approaching the critical stage who might thereafter progress to serious disability; he would, however, be no worse off after having had his periodic examination. The only harm therefore that could be done would be by the diagnosis of pneumoconiosis in a man who was not in fact affected by pneumoconiosis and might thus be unnecessarily alarmed and led to change his occupation. We feel that errors of this kind should be so infrequent as to be negligible. Such errors chiefly arise from films of poor technical quality, and these might be reduced if it were decided that every man with early pneumoconiosis should have further confirmatory films taken before being advised to change his job.

The Effect on Manpower.-Meiklejohn (1950) has expressed the fear that a scheme of this kind would reveal so much pneumoconiosis that large numbers of men would have to be advised to leave the industry and even if they were not so advised, there would be a danger of producing as many cases of neurosis as the number of cases of pneumoconiosis 
that would be prevented. It has been the experience of the Pneumoconiosis Research Unit that their surveys have produced no such neurosis.

- There is ample evidence that many men are greatly reassured after they have had a careful radiological examination and a personal interview with a doctor, to know that dust has not affected their lungs. It is not our view that periodic examinations would cause neurosis or that they would reduce manpower. Fear of the effects of dust can be a bar to recruitment ("Social Survey ", 1947). Periodic examinations should dispel this fear and thus assist recruitment. Even where fear of dust has not yet arisen, the examinations could be used to give practical demonstration to potential recruits that the community is interested in the health of its miners. There is ample testimony from other industries that medical supervision, coupled with engineering control of health hazards, is essential for the maintenance of manpower. Whether or not numbers of men would have to be advised to leave the industry because of the fact that they showed progressive simple pneumoconiosis in serial examination would depend on the effectiveness of the dust suppression now being carried out by the N.C.B. The doctor's role is to ensure that miners who are in danger of disablement by pneumoconiosis are protected, if necessary by advising them to leave the industry. It would be for the engineers to ensure that the dust levels were such that very few men would have to be so advised. Manpower is a major problem in the coal industry. A system which protected the young miner from injury to his health by this serious industrial hazard would reap a great dividend not only in human contentment but also in productivity.

\section{Summary}

A system of periodic $x$-ray examination of coal miners is suggested which should ensure the prevention of disabling pneumoconiosis.

Evidence is presented which shows that early radiological changes can be detected before serious disablement occurs, and that if men with these early changes are removed from exposure to dangerous dust they will then not develop the progressive massive fibrosis which is the cause of serious disability.

A pilot scheme would be necessary. Practical details are discussed, such as the advice to be given after the examination, the separation of the scheme from problems of compensation, the interval between radiographs, and the effect on manpower.

The periodic examination would provide a means of defining safe dust levels in different mines leading to control of the disease by economical dust suppression, meanwhile giving protection to new entrants and to workers not already affected.

\section{REFERENCES}

Baldwin, E. de F., Cournand, A., and Richards, D. W. (1948). Medicine, Baltimore, 27, 243.

Bedford, T., and Warner, C. G. (1942). J. industr. Hyg., 14, 315.

Bloomfield, J. J., Dallavalle, J. M., Jones, R. R., Dreessen, W. C.,
Brundage, D. K., and Britten, R. H. (1935). Publ. Hlth. Brundage, D. K., and

Böhme, A (1938). Beitr. Klin. Tuberc., 91, 237.
Bruce, T. (1942). Acta med. scand., suppl. 129.

Craw, J. (1947). Proc. Inst. min. Engrs. and Inst. Min. Metall. Silicosis Conf., p. 68 . London.

Davies, I., Fletcher, C. M., Mann, K. J., and Stewart, A., (1949). Proc. 9th Int. Congr. on Industr. Med., London, 1948, p. 773.

D'Silva, J. L., and Mendel, D. (1950). Thorax, 5, 325.

Eck, M., and Hanaut, A. (1944). Arch. Mal. prof., 6, 74.

Fletcher, C. M. (1948). Brit. med. J., 1, 1015, 1065 .

(1950). Report on Third Int. Conf. on Pneumoconiosis, Sydney. Ministry of National Insurance, London. To be published. -(1951). Brux.-méd. In the press.

- -, Mann, K. J., Davies, I., Cochrane, A. L., Gilson, J. C., and Hugh-Jones, P. (1949). J. Fac. Radiol., 1, 40. and Oldham, P. D. (1949). British Journal of Industrial Medicine, 6, 168.

Gilson, J. C., and Hugh-Jones, P. (1949). Clin. Sci., 7, 185.

Gough, J. (1949). Postgrad. med. J., 25, 611 . James, W. R. L., and Wentworth, J. E. (1949). J. Fac. Radiol. James, W. R. L., and Wentworth, J. E. (1949). J. Fac. Radiol.
1, 28 .'., and Aslett, E. A. (1942). Spec. Rep. Ser. med. Res. P. d'A., and Aslett, E.

Coun., Lond., No. 243.
Heppleston, A. G. (1947). J. Path. Bact., 59, 453.

Hugh-Jones, P., and Fletcher, C. M. (1950). Med. Res. Coun. Memo. No. 25. H.M.S.O. London.

Jequier-Doge, E. and Lob, M. (1944). Helv. med. Acta, 11, 123.

Lehmann, G. (1938). Arch. Gewerbepath. Gewerbehyg., 9, 58.

McVittie, J. C. (1949). Postgrad. med. J., 25, 618.

Meiklejohn, A. (1950). British Journal of Industrial Medicine, 7, 105. Motley, H. L. (1950). W. Va med. J., 46, 8.

Petersang, L. P., and Gordon, B. (1949). Amer. Rev. Tuberc., 59, 270. Peterson, J. N., Peterson, J. M., and Startup, C. W. (1939). Lancet, 1, 147 .

Rossier, P. H., Bucher, H., and Wiesinger, K. (1947). Vjschr. naturf. Ges. Zürich, 92, 83 .

Smith, J. M. (1947). Proceedings of the Institute of Mining Engineers and the Institute of Mining Metallurgists Silicosis Conference,

p. 88. London.

Sutherland, C. L., and Bryson, S. (1929). Report on the Occurrence of Silicosis among Sandstone Workers. London. H.M.S.O.

Wright, G. W. (1946). Occup. Med., 2, 546. 